\title{
PENGEMBANGAN KOMPETENSI PENDIDIK DI PERGURUAN TINGGI DALAM MENYONSONG ERA REVOLUSI INDUSTRI 4.0
}

\author{
Helaluddin ${ }^{1)}$, Hengki Wijaya ${ }^{2)}$ \\ ${ }^{1)}$ Mahasiswa Pascasarjana Prodi Ilmu Pendidikan Universitas Negeri Makassar, Sulawesi Selatan \\ Dosen Universitas Islam Negeri Sultan Maulana Hasanuddin Banten, Banten \\ ${ }^{2)}$ Mahasiswa Pascasarjana Prodi Ilmu Pendidikan Universitas Negeri Makassar, Sulawesi Selatan \\ Dosen Sekolah Tinggi Filsafat Jaffray Makassar, Sulawesi Selatan
}

\begin{abstract}
ABSTRAK
Memasuki era revolusi industri 4.0, dunia pendidikan harus segera berbenah dalam mempersiapkan diri khususnya terkait dengan sumber daya manusia di perguruan tinggi. Dosen sebagai faktor penentu dalam kemajuan pendidikan dituntut untuk selalu meng-upgrade skill dan kemampuannya. Di Indonesia, mayoritas dosen didominasi oleh generasi baby boomers dan generasi $\mathrm{X}$ atau digital immigrant yang pada praktiknya di lapangan tidak sedikit yang mengalami kendala. Salah satunya disebabkan oleh kenyataan bahwa mahasiswa sekarang merupakan generasi milenial atau digital native yang cenderung memiliki gaya dan pola belajarnya sendiri. Artikel ini menyoroti tentang kompetensi-kompetensi yang harus dikuasai oleh dosen di era revolusi industri 4.0 saat ini, yaitu: (1) educational competence, (2) competence in research, (3) competence of technological commercialization, (4) competence in future strategies, (5) counselor competence, dan (6) competence in globalization.
\end{abstract}

Kata-kata kunci: revolusi industri 4.0, pendidikan 4.0, kompetensi dosen

\section{PENDAHULUAN}

Pendidikan aba ke-21 ini tidak dapat disamakan dengan model pendidikan pada era sebelumnya. Perubahan yang cukup drastis dan sporadis menuntut aspek pendidikan itu sendiri untuk menjadi bagian penting dalam memberi arah kemajuan bagi kehidupan manusia. Topik faktual yang kini riuh diperbincangkan dalam forum-forum ilmiah baik bidang pendidikan, politik, dan ekonomi adalah hadirnya era revolusi generasi keempat, yang lebih familiar disebut dengan industry revolution 4.0 atau disingkat IR4.

Sejarah revolusi industri dimulai pada akhir abad ke-18 yang ditandai dengan munculnya berbagai peralatan yang didukung oleh mesin uap air. Masa-masa ini disebut sebagai era revolusi industri 1.0. Gelombang perubahan pun terjadi kembali pada akhir abad ke-19 yang disebut dengan era revolusi industri 2.0. Pada masa ini, perubahan signifikan terlihat pada dunia industri yang berubah dengan hadirnya pabrikpabrik dengan berbasis pada energi listrik. Laju perubahan pun berlanjut pada abad ke-20 dengan hadirnya revolusi industri 3.0 ditandai dengan penggunaan teknologi elektronik yang digunakan dalam proses produksi di pabrik-pabrik. Pada era ini banyak terjadi pengurangan tenaga kerja atau buruh karena penggunaan tenaga manusia sudah dikurangi secara drastis. Keberadaan tenaga manusia sudah tergeser oleh hadirnya peralatan mesin yang dikendalikan secara elektronik sehingga dapat manghasilkan kuantitas produksi yang lebih banyak. Kondisi ini tentu menguntungkan pihak perusahaan karena tidak perlu lagi mengeluarkan biaya produksi yang lebih besar untuk upah lembur para karyawannya.

Apa kaitannya revolusi industri 4.0 dengan bidang pendidikan? Revolusi industri 4.0 secara tidak langsung memang menuntut dunia pendidikan untuk berbenah. Dengan karakteristik dunia kerja pada era ini

\footnotetext{
${ }^{1}$ Korespondensi penulis: Hengki Wijaya, Telp 085298038071, hengkilily1988@gmail.com
} 
tentu saja berefek pada berubahnya jenis pekerjaan yang tersedia. Ada banyak pekerjaan yang menghilang karena memang sudah tidak dibutuhkan lagi. Berubahnya jenis pekerjaan tentu saja menuntut berbagai keahlian baru yang harus dimiliki oleh lulusan universitas. Menurut paparan Wold Economic Forum (2015) pada tahun 2020 ada sepuluh jenis keterampilan (skill) yang relevan dengan era revolusi industri 4.0, yaitu: (1) complex problem solving, (2) coordinating with others, (3) people management, (4) critical thinking, (5) negotiation, (6) quality control, (7) service orientation, (8) judgement and decision making, (9) active learning, dan (10) creativity.

Tantangan bagi kampus di era revolusi industri 4.0 tidak hanya berhubungan dengan upaya mempersiapkan lulusan dengan berbagai skill di atas. Hal yang tak kalah penting adalah menyiapkan sumber daya manusia khususnya tenaga dosen. Perbedaan generasi antara dosen dan mahasiswa dinilai sebagi faktor utama penyebab ketidakberhasilan pendidikan. Mengapa demikian? Dosen yang mengajar di perguruan tinggi mayoritas berasal dari generasi X, dan Y memiliki karakteristik yang berbeda dengan mahasiswa yang kini banyak dihuni oleh generasi $\mathrm{Z}$. Generasi $\mathrm{Z}$ yang lekat dengan alat digitalnya tidak cocok dengan metode pembelajaran yang ditawarkan oleh para dosen. Penggunaan metode konvensional dalam pembelajaran bagi generasi $\mathrm{Z}$ merupakan sesuatu hal yang tidak menarik. Gap atau perbedaan itulah yang menjadi masalah tunggal terbesar yang dihadapi oleh dunia kampus saat ini (Prensky dikutip Jones dan Shao, 2011).

Dengan demikian, perlu adanya pengembangan kompetensi dosen secara berkesinambungan di seluruh kampus. Pengembangan ini bertujuan agar kualitas pembelajaran dan lulusan perguruan tinggi sesuai dengan tuntutan dunia kerja di era revolusi industri 4.0.

\section{METODE PENELITIAN}

Metode penelitian yang digunakan adalah kajian kepustakaan (library research) yang menjelaskan secara teori tentang argumen penulis mengenai kompetensi dosen di perguruan tinggi di saat ini dan yang akan datang. Artikel ini menyoroti tentang beberapa kompetensi dosen yang harus segera dikuasai, antara lain: (1) educational competence, (2) kompetensi dalam penelitian, (3) kompetensi komersialiasasi teknologi, (4) competence in future strategies, (5) counselor competence, dan (6) competence in globalization.

\section{HASIL DAN PEMBAHASAN \\ Pendidikan Era Revolusi Industri 4.0}

Dengan bergulirnya era revolusi industri 4.0, tentu saja berdampak pada bidang pendidikan khususnya pendidikan tinggi. Setiap kampus harus berbenah dan mengubah paradigma pembelajaran yang selama ini digunanakan. Pembelajaran era milenial ini tidak lagi dibatasi sekat-sekat ruang kelas tetapi sudah tanpa batas. Penggunaan teknologi digital dan media sosial dianggap lebih sesuai dengan model pembelajaran saat ini. Bahkan, sudah dimungkinkan pembelajaran dapat dilakukan di rumah masing-masing mahasiswa dengan memanfaatkan teknologi.

Hal yang patut diperhatikan dalam pelaksanaan pendidikan di perguruan tinggi adalah menyediakan sarana dan prasarana yang memadai. Bahkan sudah menjadi hal yang wajib disediakan oleh pihak perguruan tinggi adalah akses internet yang memadai di lingkungan kampus. Bahkan ke depan, perguruan tinggi sudah harus bermigrasi menuju e-campus dengan menyediakan e-laboratioum, e-services, perpustakaan elektronik atau $e$-library, pembelajaran online atau e-learning, tutor online atau e-lecturer hingga penyusunan dan revisi tesis secara elektronik atau $e$-thesis (Djatmiko, 2018).

Secara garis besar, peran utama yang mendasar dari pendidikan tinggi ada tiga macam, yaitu pengajaran, penelitian, dan pelayanan. Jika dibandingkan dengan Indonesia, peran perguruan tinggi tersebut dikenal dengan istilah Tridharma Peguruan Tinggi, yaitu pegajaran, penelitian, dan pengabdian masyarakat. Namun hingga kini, mayoritas perguruan tinggi di Indonesia belum memberikan pelayanan terbaiknya bagi mahasiswa. Aspek pendukung di kampus masih bersifat konvensional dan terkesan "mempersulit" bagi mahasiswa. Bagaimana seharusnya pendidikan tinggi menempatkan dirinya di era revolusi industri 4.0? Dari ilustrasi di atas, perguruan tinggi harus segera berubah dan menyesuaikan diri dengan era saat ini. Ada beberapa hal yang menjadi poin-poin penting dalam transformasi sistem pendidikan tinggi, yaitu: (1) kurikulum berioentasi pada masa depan, (2) tenaga pengajar profesional, (3) paparan awal di tempat kerja, (4) kesepakatan baru tentang lifelong learning, dan (5) keterbukaan terhadap inovasi pendidikan (WEF, 2017). 


\section{Kompetensi Dosen Era Revolusi Industri 4.0}

Sebelum mengulas tentang kompetensi dosen di era ini, ada baiknya sedikit mengulik definsi kata kompetensi. Jika dibandingkan dengan bahasa Inggris, kata kompetensi merujuk pada kata competence dan competency. Di sisi lain, kata kompetensi juga sulit dibedakan dengan beberapa kata lain yang memiliki makna yang hampir sama, seperti skill atau ability. Namun dalam dunia pendidikan saat ini, istilah yang populer digunakan adalah learning outcome.

Menurut Grant dan Young (2010) kurangnya pendefinisian yang jelas antara kata competence dan competency menyebabkan kedua kata ini digunakan secara berbeda-beda pada berbagai aspek atau bidang dan beberapa negara. Berdasarkan penggunaannya di berbagai negara, kedua kata itu dapat dibedakan secara sederhana. Compentece merupakan istilah yang sering digunakan di negara Inggris sedangkan competency adalah konsep yang dipengaruhi oleh cara berpikir orang-orang di Amerika Serikat. Sederhananya, competences merujuk pada output yang dibutuhkan dalam standar minimum secara spesifik sedangkan competencies adalah input yang dibawa seseorang ke dalam pekerjaanya yang menghasilkan kinerja yang baik (Trotter dan Ellison dikutip Sten, 2012).

Ada berbagai jenis kompetensi bagi guru dan dosen yang dikemukakan oleh para ahli. Salah satunya dari United Nations Educational, Scientific and Cultural Organization (UNESCO) yang menyebut ada kompetensi penting di abad ke-21 ini. Kompetensi bagi guru dan dosen yang dimaksud UNESCO tersebut adalah kompetensi Information Communication and Technology (ICT). Ada tiga pendekatan yang digunakan dalam pengembangan kompetensi TIK ini, yaitu: (1) literasi teknologi, (2) knowledge deepening, dan (3) knowledge creation. Jika merujuk pada Undang-Undang Nomor 14 tentang Guru dan Dosen tahun 2005, ada beberapa kompetensi yang dipersyaratkan bagi tenaga tengajar ini. Berbagai kompetensi ini harus dipenuhi agar dapat dikatakan sebagai pengajar yang profesional. Dengan terpenuhinya berbagai kompetensi tersebut, seorang pengajar dapat memperoleh sertifikat sebagai pendidik. Kompetensi yang dimaksud adalah kompetensi pedagogik, profesional, sosial, dan kepribadian. Di samping kompetensi utama tersebut, seorang dosen juga dituntut memiliki berbagai keterampilan pendukung lainnya, seperti kompetensi kelincahan, inovasi, kreativitas, antisipasi, eksperimen, keterbukaan pikiran, dan jaringan atau networking (Harto, 2018).

Mengingat semakin sengitnya persaingan di era revolusi industri 4.0, maka profesi dosen juga harus dikembangkan seiring dengan laju perkembangan zaman. Untuk itulah, beberapa kompetensi dosen di era pendidikan 4.0 harus dikuasai, yaitu: (1) educational competence; kemampuan dasar di era ini yang merujuk pada internet of things, (2) competence in research; kompetensi dosen dalam bidang penelitian dan arahnya ke depan, (3) competence for technological commercialization; kompetensi dalam proses komersialisasi hasil penelitian dan inovasi, (4) competence in globalization, (5) counselor competence, dan (6) competence in future strategis.

\section{Educational Competence}

Kompetensi dosen di era ini tidak dapat disamakan dengan kompetensi era sebelumnya. Dewasa ini, kehadiran Internet of Things (IoT) telah menjadi bagian dari kehidupan manusia. Dengan demikian, kemampuan dalam memahami dan menggunakan berbagai peralatan berbasis IoT untuk bidang pendidikan dan oengejaran harus dikuasai. IoT adalah sebuah kondisi yang memungkinkan manusia atau benda-benda dapat terhubung dengan siapa saja, di mana saja, dan kapan saja. IoT merupakan sebuah teknologi relatif baru yang muncul untuk memfasilitasi antara yang nyata dan benda virtual (Abbasy dan Quesada, 2017).

IoT dalam kehidupan sehari-hari sudah sangat lumrah kita temui. Beberapa contoh IoT yang dimaksud adalah transpotasi daring (gojek, grab), e-commerce, pemesanan tiket pesawat dan kereta api via daring, live streaming, dan lain-lain. Dalam bidang kesehatan pun IoT juga sudah mulai diterapkan. Dengan menggunakan peralatan kesehatan yang terkoneksi internet, seorang dokter dapat mengecek tekanan darah dan beberapa tes kesehatan dari pasiennya. Dalam bidang pendidikan, contoh nyata penerapan IoT adalah pemberlakuan pembelajaran secara elektronik atau e-learning, pendidikan jarak jauh (distance learning), perpustakaan digital (digital library), e-commerce bagi UMKM kampus, dan lain-lain. Untuk itulah, kompetensi dosen harus terus di-upgrade dengan membiasakan diri dengan berbagai peralatan yang terkoneksi dengan IoT dalam proses pembelajaran.

Dalam pembelajaran bahasa Inggris misalnya, IoT juga sudah digunakan oleh beberapa guru dan dosen dengan menggunakan sensor suara dan sensor visual dalam mendeteksi kesalahan pengucapan atau 
pronouncation (Bakri, 2016). Pembelajaran dengan sistem interaktif ini dinilai akan meningkatkan semangat dan motivasi mahasiswa dalam belajara bahasa.

\section{Competence in Research}

Salah satu tugas dosen selain mengajar dan melaksanakan pengabdian kepada masyarakat adalah penelitian. Dalam menjalankan tugas penelitian, tentu saja dosen harus menguasai berbagai keterampilan dalam penelitian. Tidak banyak literatur yang menuguhkan definisi dari keterampilan dalam penelitian. Namun, Badke mengungkapkan bahwa keterampilan penelitian merupakan keterampilan untuk mengenali masalah, mengidentifiaksi sumber-sumber informasi yang tepat untuk menanggapi masalah, menilai kulaitas dari relevansi informasi yang ditemukan, dan menggunakan informasi secara efektif untuk mengatasi masalah tersebut (Garg, Madhulika, dan Passey, 2018).

Lantas, apa sajakah yang tergolong dalam keterampilan penelitian ini? Menurut Easterby-Smith dikutip Garg, Madulika, dan Passey (2018), ada beberapa kategori yang harus dimiliki oleh peneliti yang efektif, yaitu: (1) kapabilitas dan pengetahuan yang beragam seperti pengetahuan pada disiplin ilmu yang dimiliki dan keterkaitannya dengan sub-sub disiplinnya, (2) kemampuan dalam menggunakan metode penelitian, (3) kemampuan dan pengetahuan tentang metode pengumpulan data, (4) keterampilan retorikal dalam menyusun argument logical dan persuasif, (5) manajemen dan pemanfaatan waktu, (6) kapabilitas bekerja dalam kelompok, (7) keterampilan menulis dan presentasi, (8) keterampilan komputer, dan (9) kemampuan secara kontinyu menemukan solusi dalam mengatasi permasalahan.

Di era revolusi industri ini, kompetensi dalam penelitian juga merambah ke ranah yang lebih luas. Setiap dosen diharapkan mampu membangun jaringan dalam mengembangkan ilmu pengetahuan dan penelitian. Di samping itu, dosen juga harus terampil dan cekatan dalam melihat tren penelitian dunia agar mampu menentukan arah riset dan mendapatkan bantuan/hibah penelitian dari luar negeri.

\section{Competence for Technological Commercialization}

Perguruan tinggi dapat dikatakan sebagai pusat inovasi ilmu pengetahuan dan teknologi. Namun pada pelaksanaannya, banyak kampus yang mengalami kendala dalam mengkomersialisasikan inovasinya tersebut. Komersialisasi teknologi yang baru ditemukan oleh dosen atau kampus memiliki dampak yang cukup signifikan terhadap pertumbuhan ekonomi, ilmu pengetahuan \& teknologi, kampus, dan industri secara berkelanjutan. Namun, mayoritas proyek komersialisasi di Indonesia tidak dapat mencapai hasil yang memuaskan karena risiko yang terlalu besar dan sifatnya yang tidak pasti.

Menurut Jolly dikutip Zhang dan Shi (2016) komersialisasi teknologi merujuk maknanya pada proses yang dimulai dengan wawasan pasar-tekno dan diakhiri dengan fungsi berkelanjutan dari produk yang dibutuhkan pasar. Lebih lanjut, Block dan McMillan menjabarkan ada beberapa hal penting agar proses komersialisasi dapat berjalan sukses, yaitu: (1) penyelesaian konsep dan pengujian produk, (2) penyelesaian purnarupa (prototipe), (3) pembiayaan pertama, (4) penyelesaian uji pabrik pertama, (5) pengujian pasar, (6) memproduksi start-up, dan (7) melihat reaksi kompetitif pertama.

Ke depan, diharapkan dosen memiliki kompetensi dalam mengkomersialisasikan teknologi ke luar kampus bahkan hingga ke luar negeri. Salah satunya adalah hasil riset berbasis kolaborasi dengan mahasiswa atau inovasi hasil temuan yang memiliki nilai jual di masyarakat. Hasil inovasi dan penelitian seharusnya tidak hanya dijadikan bahan laporan saja yang menumpuk di gudang tetapi juga harus dikomersialisasikan ke khalayak untuk mendapatkan profit.

\section{Competence in Globalization}

Ada beberapa kompetensi yang harus diimplementasikan dalam kurikulum sekolah maupun perguruan tinggi. Menurut Pawlowski dan Holtkamp (2012) ada tujuh kompetensi global, yaitu: (1) kompetensi umum atau generic competence, (2) kompetensi IS atau Information System, (3) kompetensi TIK, (4) kompetensi manajemen proyek dan kepemimpinan, (5) kompetensi manajemen pengetahuan dan kolaborasi, (6) kompetensi komunikasi, dan (7) kompetensi intercultural.

Selanjutnya, Sten (2012) menjabarkan subkompetensi dari masing-masing kompetensi di atas. Secara ringkas dapat dilihat pada tabel berikut ini. 
Tabel 1. Kompetensi dan Deskripsinya

\begin{tabular}{|c|c|}
\hline Kategori & Deskripsi kompetensi \\
\hline Kompetensi TIK & $\begin{array}{l}\text { 1. Kemampuan menggunakan TIK sesuai dengan kebutuhan } \\
\text { bisnis } \\
\text { 2. Memahami kelebihan dan kelemahan dari perbedaan } \\
\text { sumber-sumber informasi } \\
\text { 3. Kemampuan menemukan informasi yang berkualitas } \\
\text { dengan bantuan TIK } \\
\text { 4. Kemampuan mengidentifiaksi masalah dengan TIK }\end{array}$ \\
\hline $\begin{array}{l}\text { Kompetensi kepemimpinan dan } \\
\text { manajemen proyek }\end{array}$ & $\begin{array}{l}\text { 1. Kemampuan mengatur kemampuan diri sendiri } \\
\text { 2. Kemampuan menggunakan atau memanfaatkan } \\
\text { pengetahuan dan keahlian orang lain } \\
\text { 3. Kemampuan dalam bertanggung jawab } \\
\text { 4. Kemampuan membuat keputusan }\end{array}$ \\
\hline $\begin{array}{l}\text { Kompetensi manajemen pengetahuan } \\
\text { dan kolaborasi }\end{array}$ & $\begin{array}{l}\text { 1. Kemampuan membangun hubungan secara nasional dan } \\
\text { internasional dan jaringan pada level professional } \\
\text { 2. Kemampuan membagi informasi dan pengetahuan pada } \\
\text { anggota tim (kelompok) } \\
\text { 3. Kemampuan untuk resolusi bagi masalah kolaboratif } \\
\text { 4. Kemampuan dalam memehami persepektif, kebutuhan, dan } \\
\text { nilai orang lain }\end{array}$ \\
\hline Kompetensi komunikasi & $\begin{array}{l}\text { 1. Kemampuan dalam berkomunikasi secara sensitif terkait } \\
\text { dengan persoalan pribadi dan budaya } \\
\text { 2. Kemampuan mendengarkan orang lain dan } \\
\text { mempertimbangkan saran dan pemikiran mereka } \\
\text { 3. Kemampuan berkomunikasi secara jelas dan artikulatif } \\
\text { 4. Kemampuan untuk fokus pada poin-poin penting dalam } \\
\text { berkomunikasi }\end{array}$ \\
\hline Kompetensi budaya & $\begin{array}{l}\text { 1. Keterampilan berbahasa asing (Inggris, Mandarin, Arab) } \\
\text { 2. Memahami pengaruh dan implikasi budaya dalam dunia } \\
\text { kerja } \\
\text { 3. Kemampuan dalam menyesuaikan diri dengan budaya yang } \\
\text { berbeda } \\
\text { 4. Kemampuan dalam mengevaluasi perspektif, praktik, dan } \\
\text { produk dari perspektik multiple cultural }\end{array}$ \\
\hline
\end{tabular}

\section{Conselour Competence}

Tantangan dalam bidang pendidikan tidaklah ringan. Ke depan, banyak mahasiswa atau peserta didik yang mengalami depresi dan tekanan mental yang berlebihan. Depresi tersebut bukan disebabkan oleh permasalahan dalam menerima pembelajaran tetapi lebih banyak berkaitan dengan permasalahan pribadi yang semakin kompleks. Profesi dosen tidak hanya berkutat dengan proses pembelajaran saja tetapi meluas ke ranah konseling. Seorang dosen harus mampu menjadi konselor bagi para mahasiswanya dalam membrikan motivasi, semangat, dorongan, dan nasihat-nasihat bagi permaslaahan yang mereka hadapi.

Urbani menjabarkan ada 18 keterampilan dalam conselour competence yang dikategorikan dalam tiga kelompok, yaitu exploring, understanding, dan acting (Alis, Jaafar, dan Ayub, 2018). Kelompok exploring terdiri atas kontak mata, bahasa tubuh, tone suara, pertanyaan, parafrasa, dan meringkas. Tahap pemahaman atau understanding dibedakan menjadi beberapa poin, yaitu kemampuan mengidentifikasi konten dan perasaan, pengungkapan diri sendiri, ekspresi yang konkret dan nyata, urgensi, dan konfrontasi. Terakhir, tahap acting terbagi atas: (1) kemampuan membuat keputusan, (2) membuat alternative pilihan, (3) membuat ekspektasi, (4) mendapatkan persetujuan, (5) membuat janji, dan (6) meninjau semua tindakan untuk menentukan hasil. 


\section{Competence in Future Strategies}

Saat ini, kita menghadapi berbagai tantangan yang tidak dapat diprediksi dari berbagai aspek sebagai akibat dari globalisasi dan laju perkembangan teknologi. Ketidakmapuan manusia dalam menebak kejadian masa depan setidaknya dapat diantisipasi dengan kemampuan setiap individu untuk memprediksi kemungkinan yang akan terjadi. Dosen sebagai ujuk tombak di perguruan tinggi harus mampu memprediksi dan memperkirakan berbagai kemungkinan yang terjadi dalam dunia pendidikan.

Menindaklanjuti persoalan tersebut, dosen harus terus berupaya mengembangkan jariangan dan link-nya ke seluruh dunia. Jaringan ini dapat dibangun melalui berbagai aktivitas akademik seperti: (1) menjalin kerjasama bidang penelitian (penelitian kolaboratif dengan kampus luar negeri), (2) program joint-lecturer, (3) pertukaran pegawai kampus, dan lain-lain. Dengan banyak mengikuti kerja sama dengan berbagai kampus di seluruh dunia akan berdampak positif terhadap perkembanagan kampus dalam negeri. Setidaknya, laju pergerakan kampus di Indonesia tidak tertinggal jauh dari isu-isu global dalam dunia pendidikan.

\section{KESIMPULAN}

Tantangan kian berat bagi para pendidik di era revolusi industri 4.0 saat ini. Gempuran teknologi digital mau tidak mau berimbas pada dunia Pendidikan. Banyaknya jenis pekerjaan yang hilang dan digantikan dengan jenis pekerjaan baru menuntut lulusan perguruan tinggi untuk menguasai berbagai kompetensi yang sesuai dengan karakteristik revolusi industri 4.0. Dalam memenuhi tujuan tersebut, maka posisi dosen sebagai ujung tombak perguruan tinggi dituntut untuk mengembangkan kompetensinya juga.

Dalam Undang-undang Nomor 14 tahun 2005 tentang Guru dan Dosen telah dipaparkan berbagai kompetensi yang harus dikuasai oleh guru dan dosen. Namun, seiring dengan arus globalisasi dan kemajuan teknologi digital maka ada beberapa kompetensi yang perlu juga dikuasai oleh dosen. Beberapa kompetensi yang dimaksud adalah educational competence, competence in research, competence for technological commercialization, competence in globalization, conselour competence, dan competence in future strategies.

\section{DAFTAR PUSTAKA}

Abbasy, M.B. \& Quesada, E.V. 2017. Predictable Influence of IoT (Internet of Things) in Higher Education. International Journal of Information and Education Technology, 7(12), 914-920.

Alis, N., Jaafar, W.M.W., \& Ayub, A.F.M. 2018. Promoting Counseling Competence Using Self-Reflection. MATEC Web of Conference 150. Kuala Lumpur: EDP Science

Bakri, M.A. 2016. Studi Awal Implementasi Internet of Things pada Bidang Pendidikan. JREC: Jurnal of Electrical and Electronic, 4(1), 18-23.

Djatmiko, M.B. 2018. Perubahan SDM Pendidikan Tinggi Era Revolusi Industri 4.0. Materi disajikan dalam Kuliah Umum Universitas Gunadharma. Jakarta: Universitas Gunadharma

Garg, A., Madhulika, M., \& Passey, D. 2018. Research Skills Future in Education: Building Workforce Competence. Laporan Penelitian Kolaborasi antara Centre for Technology Enhanced Learning dan Lancaster University.

Grant, S. dan Young, R. 2010. Concepts and Standarization in Areas Relating to Competences. International Journal of IT Standards and Standarization Research, 8(2), 29-44.

Harto, K. 2018. Tantangan Dosen PTKI di Era industri 4.0. Jurnal Tatsqif: Jurnal Pemikiran dan Penelitian Pendidikan, 16(1), 1-15.

Jones, C., \& Shao, B. 2011. The Net Generation and Digital Natives: Implications for Higher Education. Higher Education Academy. Milton Keynes: The Open University

Pawlowski, J.M. \& Holtkamp, P. (2012). Toward on Internalization of the Information Systems Curriculum. Dalam Prosiding MKWI 2012 (Multi Conference Business Information System), Braunscweig: Maret 2012

Sten, Tiia. 2012. Assessing Globalization Competences in The Information System Domain-Instruments and Methods. Jyvaskyla: University of Jyvaskyla

Undang-Undang Republik Indonesia Nomor 14 Tahun 2005 tentang Guru dan Dosen. Jakarta: Depdiknas

UNESCO. 2011. UNESCO ICT Competency Framework for Teachers. Paris: UNESCO

World Economic Forum (WEF). 2015. New Vision for Education: Unlocking The Potential of Technology. Geneva: WEF

World Economic Forum (WEF). 2017. Realizing Human Potential in The Fourth Industrial Revolution: An Agenda for Leaders to Shape the Future of Education, Gender and Work. Geneva: WEF 
Zhang, Y. dan Shi, P.Y. 2016. Core Competencies for Commercialising Emerging Technologies. https: //www.researchgate.net/publication/267718249. Diunduh pada 12 Januari 2019. 